\title{
Relatos de experiência: uma contribuição freiriana para pensar o trabalho do tutor virtual
}

\author{
Experience report: a Freireian contribution to thinking about the work of the \\ virtual tutor
}

\author{
Maria Valdinete de Pontes Matias' \\ João Batista Gonçalves Bueno²
}

\section{Resumo}

Este estudo tem como característica principal apresentar uma experiência didáticopedagógico em ambiente virtual de aprendizagem no curso: "Mediadores Pedagógicos Digitais para EaD”, oferecido pelo Centro de Promoção para a Inclusão Digital, Escolar e Social (CPIDES) através da Pró-reitora de Extensão da Universidade Estadual Paulista (PROEX/Unesp). Partimos das concepções elaboradas por Paulo Freire como percussor da educação brasileira, desenvolvendo práticas de diálogo como para interação nas mais variadas formas de comunicação. Neste sentido, refletimos sobre o trabalho desenvolvido em plataformas digitais considerando os atos de construções de relações virtuais entre os professores que valorizam o reconhecimento dos saberes um dos outros. As ações foram realizadas entre os meses de dezembro a maio de 2019, quando na oportunidade foi realizado atividades na função de Tutora Virtual. Assim, pretende-se apresentar o trabalho desenvolvido neste curso, deixando explícito sua relevância para o uso das tecnologias digitais. Considerando, também a importância do papel do professor/tutor/formador, como estimulador de práticas de diálogo que valorizam a produção de conhecimentos educacionais. Vale salientar que a contribuição de Paulo Freire teve relevância neste trabalho por constituir indicadores significativos mediados pelo diálogo e a interação em Educação à Distância. Isto se deu pelo desenvolvimento do processo da mediação pedagógica no campo da educação atual, modelo que promoveu a comunicação assíncrona e contribuiu para estabelecer relações entre os sujeitos participantes desse modelo de ensino em contexto virtual.

Palavras-chave: Educação. Tutor Virtual. Diálogo e Interatividade. Mediação Pedagógica.

\footnotetext{
Abstract

The main characteristic of this study is to present a didactic-pedagogical experience in a virtual learning environment in the course: "Digital Pedagogical Mediators for EaD", offered by the Center of Promotion for a Digital, School and Social Inclusion (CPIDES)

${ }^{1}$ Mestranda do Programa de Pós-Graduação em Formação de Professores - PPGFP da Universidade Estadual da Paraíba-UEPB. E-mail: valdinetepontesm@gmail.com

2 Professor adjunto do curso de História da UEPB , CH , campus III , membro permanente dos programas de mestrado: PPGFP da UEPB e PPGH da UFPB. E-mail :joaobgbueno@hotmail.com
} 


\section{-Revista de Iniciação à Docência, v.6, n.2, 2021- \\ Publicação: dezembro, 2021 - ISSN 2525-4332}

through the Pro-Rector of Extension of the São Paulo State University (PROEX/Unesp). We start from the concepts developed by Paulo Freire as a precursor of Brazilian education, developing practices of dialogue like to interactions in the most varied forms of communication. In this sense, we reflect on the work carried out on digital platforms considering the acts of construction of virtuous relationships between teachers who value the recognition of each other's knowledge. The actions were carried out between the months of December to May 2019, when in the opportunity activities in the role of Virtual Tutor was held. In addition, it intends to present the works carried out in this course, explaining its relevance for or using digital technologies. Also considering the importance of the role of the teacher/tutor/trainer, as a stimulator of dialogical practices that value the production of educational knowledge. It is noteworthy that Paulo Freire's contribution is relevant to this work for constitutes significant indicators mediated by dialogue and the interaction in Distance Education. This is due to the development of the pedagogical mediation process in the current field of education, a model that promotes asynchronous communication and contributes to establishing relationships between the subjects participating in this teaching model in a virtual context.

Keywords: Education. Virtual Tutor. Dialogue and Interactivity. Pedagogical Mediation.

\section{Introdução}

Este artigo discute as práticas educacionais desenvolvidas pela formação e atuação de tutores virtuais nos cursos em EAD. Tem sua fundamentação nos estudos de Paulo Freire o qual contribuiu para entendimento do diálogo como ferramenta para interação nas mais variadas formas de comunicação entre os sujeitos. Neste sentido, se fez necessário compreender como as práticas de diálogo virtual são potencializadoras para a problematização das condições de trabalho vividas pelos professores e, consequentemente pelos cursistas/aluno.

A prática docente e sua mediação pedagógica é constituída pela articulação entre teoria e prática, ou seja, é o refletir sobre a própria atividade - a chamada "práxis". Nesta perspectiva, à modalidade de ensino à distância, não obstante, também requer uma perspectiva dialógica e interativa as quais envolva os sujeitos e aproximem assim o conhecimento. (FREIRE, 2002), na qual apresento uma experiência realizada no ambiente virtual de aprendizagem onde atuei na qualidade de tutor/professor/formador.

Esta reflexão tem sua relevância no contexto da educação atual, por evidenciar novas ações no âmbito da educação à distância -- EaD para a propiciar aos sujeitos envolvidos uma aprendizagem significativa em contextos de comunicação assíncronas e, assim, proporcionar novas competências e habilidades ao ensino e a aprendizagem "on-line". de forma criativa e participativa.

O presente estudo parte das seguintes questões: $O$ trabalho do tutor/professor/mediador foi significativo para mediação pedagógica em ambientes virtuais de aprendizagem? Houve interações e feedbacks subjetivos ao trabalho em EaD? 


\section{-Revista de Iniciação à Docência, v.6, n.2, 2021- \\ Publicação: dezembro, 2021 - ISSN 2525-4332}

Em que este curso contribuiu para ampliação do conhecimento de forma virtual? A mediação foi relevante, de modo a desenvolver uma escuta sensível entre os participantes, no que lhe concerne, promoveu diálogo e interatividade?

Dialogar com Paulo Freire, torna-se necessário nesta pesquisa por reconhecer suas contribuições ao trabalho pedagógico desenvolvido pelos docentes nas escolas. Desse modo, sua fala nos recorda a prática docente revelada por saberes que considero essenciais para formação crítica e reflexiva em contextos educativos. Assim, a presente discussão, traz consigo a necessidade de nos tornarmos enquanto professores, sujeitos produtivos de conhecimentos. Portanto, o pensamento freiriano nos faz entender, principalmente que "ensinar não é transferir conhecimentos, mas criar as possibilidades para sua produção ou a sua construção." (FREIRE, 2002, p. 12).

É possível destacar que as ações desenvolvidas no curso coadunam com o pensamento de Paulo Freire. Isto se dá quando que aos estudantes caminham por uma via de mão dupla entre o ensinar e aprender de forma dialogada e interativa. É nessa interação que é possível verificar se as relações foram significativas por desenvolver-se de forma colaborativa e criativa, oportunizaram a criação, mesmo no ensino à distância, de práticas que caracterizam a mediação pedagógica, construída por um trabalho em equipe com foco na organização/intervenção/feedbacks.

Esta metodologia de ensino aprimorou a prática educativa por fomentar novas estratégias de aprendizagem. Isto se deu ao pensar nos conteúdos, atividades, aplicação de avaliação como meios de aprimoramento das ações propostas desenvolvidas pelo docente/tutor/mediador em práticas de EaD. Foi a partir dessa reflexão que se pretendeu confirmar em que a mediação pedagógica correspondente ao diálogo e interatividade contribuiu para a realização das atividades significativas em ambientes virtuais.

As atividades educacionais implementadas no curso priorizaram a escuta e a fala numa relação recíproca de interatividade e criatividade. Sobretudo, nas mudanças das práticas pedagógicas com foco na formação continuada nas novas metodologias de ensino no âmbito virtual de aprendizagem. As ações do programa fomentaram, portanto, um novo direcionamento para educação, exigindo, neste sentido, (re)pensarmos os modos que assegurem o desenvolvimento de uma discussão questionadora,

[3...ㄹ.? uma educação que possibilitasse ao homem a discussão corajosa de sua problemática. De sua inserção nesta problemática. Que o advertisse dos perigos de seu tempo, para que, consciente deles, ganhasse a força e a coragem de lutar, ao invés de ser levado e arrastado à perdição de seu próprio "eu", submetido às prescrições alheias. Educação que o colocasse em diálogo constante com o outro. Que o predispusesse a constantes revisões (FREIRE, 1967, p. 90).

Partindo deste pensamento, foi possível desenvolver um curso de formação de professores que estimulasse a produção de diálogos que potencializassem a produção de questionamentos críticos sobre a profissão docente. E, nesta perspectiva, dialogamos com a educação virtual percebendo necessidades e possibilidades ao campo do 


\section{-Revista de Iniciação à Docência, v.6, n.2, 2021- \\ Publicação: dezembro, 2021 - ISSN 2525-4332}

conhecimento em várias dimensões. Esta tarefa é também dos profissionais da educação que atuam em contextos subjetivos a ação formativa por compreender e inserir no ato de saber e fazer aprendizagens significativas para formação dos professores nesta modalidade de ensino.

\section{Metodologia}

Nesta discussão a relação vivenciada nos ambientes virtuais de aprendizagem, numa interação/mediação entre pesquisador e pesquisado. Neste caso, relato os conhecimentos adquiridos, associados aos pesquisados. Atribuindo-lhes o nome "Cursistas" para os relatos do estudo realizado para a argumentar, discutir e explicar as experiências vivenciadas neste curso de formação em educação virtual.

A revisão bibliográfica, já produzida no meio acadêmico, relativo ao desenvolvimento e avaliação das atividades construídas no ambiente de aprendizagem no contexto da EaD, (PRODANOV; FREITAS, 2013). Sendo assim, algumas análises sobre os dados coletados durante as atividades desenvolvidas pelos cursistas no curso de formação -- "Mediadores Pedagógicos Digitais para Educação a distância, foi desenvolvido um processo de investigação sobre as práticas implementadas no curso, procurando refletir criticamente sobre os contextos, através de uma abordagem qualitativa baseada na pesquisa-ação.

Isto se deu por meio da organização e questionamento dos dados produzidos no curso, analisando o plano de unidade curricular, também chamado "Contrato de Aprendizagem" entendidos como caminhos percorridos para os objetivos propostos, conteúdos, competências a desenvolver, calendário e os meios avaliativos. O curso tem como modelo de aprendizagem quatro eixos: a aprendizagem centrada no estudante, flexibilização, interatividade e inclusão digital. Apresentou ainda, processos avaliativos em modelo e-leaming avançado, utilizando a plataforma Moodle em adaptação à logística da instituição e sua organização.

As atividades formativas propuseram autonomia aos estudantes, numa construção dialógica a partir da autocorreção, feedbacks dos mediadores nas plataformas de aprendizagem. Os e-fólios trazem atividades para serem realizadas durante quatro meses organizados em módulos temáticos, com atribuições de valores seguindo os temas estudados nas unidades curriculares. Os fóruns ajudam na estruturação, dialogicidade e ainda favorece refletir sobre os conteúdos em pauta. (OLIVEIRA; LENUZZA; SCHLÜNZEN, 2021).

Portanto, os módulos trabalhados no curso apresentavam uma sistemática para os conteúdos numa abordagem significativa aos contextos virtuais de aprendizagem considerando os objetivos propostos do trabalho a ser desenvolvido nas plataformas digitais. As temáticas eram trabalhadas por módulos, conforme o quadro a seguir: 


\section{-Revista de Iniciação à Docência, v.6, n.2, 2021- Publicação: dezembro, 2021 - ISSN 2525-4332}

Quadro 1 - síntese dos conteúdos utilizados e os objetivos ${ }^{3}$ propostos para cada módulo

\begin{tabular}{|c|c|c|}
\hline \multicolumn{3}{|c|}{ DESENHO DOS CONTEÚDOS PROPOSTO POR MÓDULO } \\
\hline MÓDULO & CONTEÚDOS & OBJETIVOS \\
\hline PRIMEIRO & $\begin{array}{l}\text { Ambientes virtuais } \\
\text { de Aprendizagem }\end{array}$ & $\begin{array}{l}\text { Conhecer e familiarizar-se com diferentes formatos e } \\
\text { ferramentas de ambientes virtuais de aprendizagem; } \\
\text { identificar as características e competências de ser } \\
\text { estudante no on-line; conhecer alguns eixos da } \\
\text { organização didático-pedagógica do Modelo Pedagógico } \\
\text { Virtual da Universidade Aberta, Portugal (UAb) e do } \\
\text { Núcleo de Educação a Distância da Universidade Estadual } \\
\text { Paulista (NEaD/UNESP) }\end{array}$ \\
\hline SEGUNDO & $\begin{array}{l}\text { Mediação } \\
\text { pedagógica em } \\
\text { processo de } \\
\text { Tutoria On-line }\end{array}$ & $\begin{array}{l}\text { Identificar as características e especificidades da } \\
\text { comunicação mediada pela tecnologia; explorar os } \\
\text { conceitos de interação, interatividade e mediação; aplicar } \\
\text { as competências de mediação em simulações de } \\
\text { situações práticas }\end{array}$ \\
\hline TERCEIRO & $\begin{array}{l}\text { Acessibilidade e } \\
\text { Inclusão em } \\
\text { Ambientes Virtuais } \\
\text { de Aprendizagem }\end{array}$ & $\begin{array}{l}\text { Compreender as especificidades da docência no } \\
\text { ambiente on-line; refletir sobre o papel do mediador on- } \\
\text { line no desenvolvimento das e-atividades; conhecer } \\
\text { possibilidades no uso das TDIC e na mediação on-line que } \\
\text { facilitem a acessibilidade e a inclusão; conhecer } \\
\text { estratégias pedagógicas afins com as tendências atuais } \\
\text { da educação }\end{array}$ \\
\hline QUARTO & $\begin{array}{l}\text { Avaliação em } \\
\text { contextos Digitais }\end{array}$ & $\begin{array}{l}\text { Compreender a avaliação pedagógica em contextos } \\
\text { digitais e a atuação do tutor neste processo; identificar } \\
\text { os diversos instrumentos de avaliação digital; realizar } \\
\text { autoavaliação sobre as competências pessoais e o que é } \\
\text { necessário melhorar na função da mediação tutorial. }\end{array}$ \\
\hline
\end{tabular}

Fonte: dados da pesquisa.

As atividades tiveram diversos formatos, foram realizadas de forma individual como colaborativas, na plataforma moodle e da "web" 2,0. Foi criado um espaço para os estudantes terem acesso à atualização das novas ferramentas. Com a criação um do Whatshapp houve maior interação e comunicação entre todos os envolvidos no curso sendo totalmente assíncrona com fomento ao desenvolvimento dos conteúdos, sobretudo, entre estudante e o tutor numa avaliação sistemática, com feedbacks direcionados e contínuos.

\footnotetext{
3Os objetivos apresentados neste quadro têm origem no texto: "Projeto UNESP, UAb e CAPES: formação de mediadores pedagógicos digitais para a educação a distância." (OLIVEIRA; LENUZZA; SCHLÜNZEN, 2021, p. 4-5).
} 


\title{
-Revista de Iniciação à Docência, v.6, n.2, 2021- \\ Publicação: dezembro, 2021 - ISSN 2525-4332
}

Para iniciar cada módulo a equipe organizadora realiza encontros: webconferências formativa com os tutores para orientação dos conteúdos as serem trabalhados no curso. Antes de cada agenda semanal as supervisoras do curso utilizam a ferramenta meu E-mail enviava informações aos Tutores, eles utilizavam nas agendas com os cursistas recorrendo à mesma ferramenta de comunicação. Pensando na organização, do fórum, era criado tópicos para cada módulo, assim a equipe disponibilizava as orientações aos tutores utilizarem na plataforma, fóruns com os cursistas. Havia uma interação recíproca, diálogo permanente entre estudantes e tutores, utilizando-se de meios de compartilhamentos a exemplo do uso das estratégias pedagógicas relevantes como: personalização, a gamificação, trilhas e os recursos educacionais abertos. Nestes contextos,

\begin{abstract}
entende-se essa iniciativa como parte do aprimoramento dos processos de accountability da própria UAB-Br, na medida em que se fundamenta como ação gerencial integradora à qualidade dos cursos, o que permitirá o estabelecimento de uma cultura colaborativa entre as diversas instâncias, trazendo a possibilidade de otimização e melhor acompanhamento da aplicação dos recursos financeiros e de pessoal, e permitindo ainda atender de maneira mais adequada as exigências de prestação de contas em âmbito público. (OLIVEIRA; LENUZZA; SCHLÜNZEN, 2021, p. 60).
\end{abstract}

Desta feita, a produção de análises sobre quais processos de significação foram produzidos pelos participantes. Para depois identificarmos quais eram as necessidades de mudanças nas práticas dos professores em sala de aula e produzir possíveis soluções, (THIOLLENT, 1997, 1997).

Considerei, também a relevância do estudo qualitativo de Alves numa dimensão: "visão holística, abordagem indutiva e investigação naturalística." (1991, p. 54). Tal perspectiva nos fez reconhecer conforme Severino (2007) que os observadores mergulham nos campos de estudo e, assim trocam experiência com as pessoas.

A partir dessa premissa, se organizou as ideias com o levantamento dos documentos relacionados com à problemática de investigação e análise explicativa. Foi estabelecido, desta maneira, as delimitações dos objetivos propostos à pesquisa, ou seja, buscar reforço na dialogicidade freiriana promovida pela interação entre os sujeitos nas plataformas digitais.

\section{Fundamentação Teórica}

Atualmente, nesta segunda década do século XXI, a Educação a Distância (EaD) vem produzindo modelos e práticas de ensino significativos baseados na comunicação assíncrona estabelecida pela comunicação virtual. Desse modo, o tutor/professor/formador "on-line" pode se apropriar desse conhecimento, construindo novos significados sobre os processos de ensino e aprendizagem virtuais. Instituindo, 


\section{-Revista de Iniciação à Docência, v.6, n.2, 2021- \\ Publicação: dezembro, 2021 - ISSN 2525-4332}

assim, novos saberes, de modo a produzir significados para suas vidas cotidianas e de trabalho por meio das plataformas digitais.

Fagundes (2003), comenta que os professores não precisam fazer cursos, ou completar formações para começar a utilizar as tecnologias digitais. Os professores precisam ter mais segurança porque, às vezes, parecem assustados para empregar tecnologia em suas aulas. Por isso, no "Estar Junto Virtual” a avaliação formativa é o parâmetro e o processo de ensinar e aprender, é prioridade.

Por conseguinte, imerge no campo da educação à distância novas possibilidades de ensino e aprendizagem, evidenciando direcionar o aprendiz a descobrir e vislumbrar novos conhecimentos. Para tanto, surge no cenário da educação em EaD propostas de mediação pedagógica que primam por desenvolver práticas educativas acolhedoras e dialógicas numa perspectiva de ensino e aprendizagem, colaborativa, interativa e criativa. Isto se dá, de modo que os formadores/mediadores/tutores inseridos nesse processo mantenham contato com os estudantes/cursistas utilizando o AVA4.

Desta feita, concebe-se que as tecnologias digitais contribuem para efetivação de práticas criativas e, de forma sistemática ajudam na interação e promovem uma comunicação assíncrona. Sendo, portanto, fundamental para construção de novas vivências nestes ambientes virtuais. Fernandes (2006) compreende que o avanço das tecnologias em ambientes de aprendizagem propõe uma nova relação: "as novas tecnologias agregaram as mídias o conceito de interação”. (FERNANDES, 2006, p. 133).

Portanto, busca-se agregar novos valores a utilização da tecnologia digital por meio dos cursos de formação continuada em EaD. Desse modo, as experiências vividas nestes ambientes se concretizam como produções de aprendizagens, numa lógica de comunicação interativa e coletiva, além de; significativa para a produção da mediação pedagógica desenvolvida durante os cursos em ambientes digitais.

Neste contexto, podemos usar a expressão coletividade fazendo uma relação com o que foi abordado por Tardif e Lessard (2014), quando evidenciam que as interações humanas ajudam a construir significados e dão importância a esta relação recíproca do conhecimento. Portanto, "é porque trabalha com o coletivo humano segundo modalidades de interações e de significações que o docente se confronta com outras dimensões fundamentais da complexidade de sua tarefa." (TARDIF; LESSARD, 2014, p. 72).

Essa fala das autoras nos faz refletir sobre a importância de construir relações de coletividade para perceber nova forma de atuar e, consequentemente, ensinar e aprender com significações nos contextos virtuais. A partir dessa discussão, urge, portanto, pensar as tecnologias para o desenvolvimento de novas competências. Motivo pelo qual, mobiliza um trabalho que, tem como pressuposto, enquadrar no contexto da

\footnotetext{
${ }^{4}$ Ambiente Virtual de Aprendizagem- AVA
} 


\section{-Revista de Iniciação à Docência, v.6, n.2, 2021- \\ Publicação: dezembro, 2021 - ISSN 2525-4332}

educação a distância uma mediação pedagógica constante, fomentada para o diálogo nas interações mediadas pela intervenção nas práticas "on-line”.

Discutir sobre interatividade é refletir sobre o pensamento de Freire (2002) de forma crítica sobre a nossa prática, além de, fazer análises das ações desenvolvidas na busca de melhorias e de avanço do ensino e aprendizagem.

A construção da nossa identidade é baseada nas experiências vivenciadas no cotidiano, por isso, o professor precisa experienciar novas formas de atuar enquanto profissional da educação. Acreditamos que só assim, será possível que o educando exercite a "curiosidade epistemológica" e percebendo, por análises de aspectos do seu cotidiano, que "o mundo não é. O mundo está sendo" (FREIRE, 2002, p. 30).

Esse pensamento do autor Paulo Freire, nos faz indagar: estamos dialogando sobre nossas ações para criar situações de aprendizagens significativas nos ambientes formativos "online"? Neste caso, entendo que as demandas atuais exigem que o professor avance no conhecimento e desenvolver um trabalho pedagógico que atenda às reais necessidades do estudante. $\mathrm{E}$, neste sentido o estudante virtual torna-se "mais do que ferramenta operacional, tecnologia é cultura e, como tal, interfere na configuração de modos de ser e de pensar (...)", (DUARTE, 2006, p. 139).

Para tanto, o trabalho nos ambientes digitais pode configurar uma dinâmica de aprendizagem que contribui para o desenvolvimento de competências capazes de estimular um ensino significativo e estimulador. Esse conceito de personalização é apresentado aqui por Ota (2008), o que nos leva a compreender que os processos de ensino-aprendizagem dependem também da forma como o conhecimento se apresenta para o estudante. Neste caso, deve acontecer pelas singularidades/necessidades que se apresentam no cotidiano vivenciado. Esse pensamento é dialogado por Paulo Freire e, nos revela desafios e responsabilidade para o ato de educar.

\section{A partir das relações do homem com a realidade, resultantes de estar com ela e de estar nela, pelos atos de criação, recriação e decisão, vai ele dinamizando o seu mundo. Vai dominando a realidade. Vai humanizando-a. Vai acrescentando a ela algo de que ele mesmo é o fazedor. Vai temporalizando os espaços geográficos. Faz cultura. (FREIRE, 1967, p. 43).}

O autor evoca a relevância do estudante desenvolver seu modelo de aprendizagem, todavia, centrado no autoconhecimento e autonomia, razão pelo qual se torna protagonista e membro participante da ação, interferindo significativamente no seu aprendizado. Esse modelo de estudo converge com o ensino à distância quando considera a pessoa do estudante capaz de organizar com proatividade e criatividade seu conhecimento.

A autonomia enquanto amadurecimento do ser para si, é preciso, é vir a ser. Não ocorre em data marcada. É neste sentido que uma pedagogia da autonomia tem de estar centrada em experiências estimuladoras da decisão e da responsabilidade, vale dizer, em experiências respeitosas da liberdade (FREIRE, 2002, p. 41). 


\section{-Revista de Iniciação à Docência, v.6, n.2, 2021- \\ Publicação: dezembro, 2021 - ISSN 2525-4332}

O autor traz uma contribuição relevante, de tal forma, que nos ajuda a formular questões norteadoras ao trabalho do tutor/professor/formador por fomentar evoluções, crescimento, aspirações ao trabalho educativo que prioriza o ser autônomo e proativo. Essa atividade não pode ser postergada por se tornar algo imprescindível e de fundamental relevância no cenário da educação "on-line". Por isso, deve-se buscar formas de conhecer as trilhas de aprendizagem e suas ramificações produtivas para incluir com qualidade o estudante no campo da educação virtual.

Assim, relacionando a inclusão e a EaD, para a criação e garantia de ambientes inclusivos, diversos fatores precisam ser considerados, os quais estão relacionados à mudança da cultura e de aspectos atitudinais por parte da equipe de profissionais (RIOS, 2018, p.1).

O que temos aqui é uma política de educação que almeja gerar excedente entre, apropriar e produzir no contexto da EaD. Essa ação sobrepõe o já realizado quando estimula o estudante a desenvolver potencialidades, sobretudo, em seu desenvolvimento ação capaz de avançar na aprendizagem desta modalidade de ensino. Esse movimento se torna eficaz quando o tutor/formador/mediador reconhece seu papel organiza atividades de compartilhamentos na comunicação síncrona e assíncrona nos ambientes de aprendizagem.

Para atuar e oferecer aos cursistas bons feedbacks, os tutores devem estar atentos aos cuidados básicos e aos papéis assumidos e transmitidos pelo tom da mensagem, ou pela linguagem escolhida ao elaborar a resposta ao cursista. Isso requer que eles tenham conhecimento sobre o assunto, no qual irão atuar e que o feedback considere a temática trabalhada, de forma a orientar os cursistas sobre o conteúdo que esteja sendo estudado." (ALBUQUERQUE; SCHLÜNZEN. 2018, p. 8).

Estes saberes formam um conjunto de representações, as quais, os professores interpretam, compreendem e orientam sua profissão em todas as suas dimensões que convergem para um mesmo ponto: a aprendizagem interativa, instrutiva, cooperativa, colaborativa e significativa nas suas ações. Exige novas competências e visa uma nova forma de saber e fazer nos ambientes educativos. No pensamento de Perrenoud, o termo competência tem caráter significativo porque as ações docentes evidenciam processos formativos, pois "o professor desenvolve esquemas de pensamento próprios a seu ofício." (2000, p.16)

Entre nós, repita-se, a educação teria de ser, acima de tudo, uma tentativa constante de mudança de atitude. De criação de disposições democráticas através da qual se substituíssem no brasileiro, antigos e culturológicos hábitos de passividade, por novos hábitos de participação e ingerência, de acordo com o novo clima da fase de transição. Aspecto este já afirmado por nós várias vezes e reafirmado com a mesma força com que muita coisa considerada óbvia precisa, neste País, ser realçada. Aspecto importante, de nosso agir educativo, pois, se faltaram condições no nosso passado histórico-cultural, que nos tivessem dado, como a outros povos, uma constante de hábitos solidaristas, política e socialmente, que nos fizessem menos inautênticos dentro da forma democrática de governo, restava-nos, então, aproveitando as condições novas do clima atual do processo, favoráveis à democratização, apelar para a educação, como ação 


\title{
-Revista de Iniciação à Docência, v.6, n.2, 2021- Publicação: dezembro, 2021 - ISSN 2525-4332
}

social, através da qual se incorporassem ao brasileiro estes hábitos. (FREIRE, 1967, p. 94).

Paulo Freire, é insistente nesta fala a nos fazer pensar na mudança de atitude, sair do comodismo e, partir para novas formas de fazer educação. Esse pensamento converge com as demandas atuais, quando incorpora visões sociopolíticas e culturais avançadas, de forma que nos situemos no tempo em busca de criações reformulações. Essa temática nos instiga a entender o diálogo como ferramenta para novas discussões e atuações. Precisamos conversar, sobre nossas experiências de forma a construir interações significativas ao ensino e aprendizagem e, assim, compartilhar saberes e fazeres.

\begin{abstract}
A experiência, a possibilidade de que algo nos acontece ou nos toque, requer um gesto de interrupção, um gesto que é quase impossível nos tempos que correm: requer parar para pensar, parar para olhar, parar para escutar, pensar mais devagar, olhar mais devagar, e escutar mais devagar; parar para sentir, sentir mais devagar, demorar-se nos detalhes, suspender a opinião, suspender o juízo, suspender a vontade, suspender o automatismo da ação, cultivar a atenção e a delicadeza, abrir os olhos e os ouvidos, falar sobre o que nos acontece, aprender a lentidão, escutar aos outros, cultivar a arte do encontro, calar muito, ter paciência e dar-se tempo e espaço. (LARROSA, 2015, p. 25).
\end{abstract}

Objetiva-se entender em que se baseia o conceito experiência expressada por este autor e, compreender que, o professor na sua trajetória acumula ao longo das experiências, novos saberes, sobretudo, associados a novas descobertas e inquietações, esses desafios não se dão apenas em meio a aquisição de novos conhecimentos, mas acontece pela reflexão crítica nos fazeres da prática cotidiana necessária para atuação.

Urge, a necessidade de refletir sobre a ação dos tutores e sua relevância no contexto da educação a distância, de forma a incluir com significado novos saberes aos cursistas/estudantes, tendo como parâmetro a inserção de novas práticas, contribuindo para permanência do estudante no ambiente virtual de aprendizagem, incluindo com qualidade, prevenindo a exclusão sociopolítica, e cultural tão arraigada no contexto da educação.

Severino (2015), faz comentários em relação às pesquisas e diz que para essa prática "várias são as modalidades", no entanto, eixos norteadores a necessários para ter, sobretudo, "coerência epistemológica, metodológica e técnica". (2015, p, 118). Tais procedimentos, contribuem para o desenvolvimento eficaz durante sua realização. Por isso, a reflexão sobre o trabalho desenvolvido ganha sentido e se concretiza por parâmetros de educação de qualidade, que busca trabalhar nos ambientes de aprendizagem suas especificidades, contribuindo com a aprendizagem significativa.

Essas ações têm como prioridade a participação efetiva de todos os cursistas/estudantes no processo educativo, entendendo que "ensinar não é transferir conhecimentos, mas criar as possibilidades para sua produção ou a sua construção." (FREIRE, 2002, p. 12). Esse pensamento é de prioridade do ensino em EaD e concretiza-se 


\section{-Revista de Iniciação à Docência, v.6, n.2, 2021- \\ Publicação: dezembro, 2021 - ISSN 2525-4332}

nas mais variadas formas de aprender, evidentemente, nas relações de diálogo e interação entre os tutores/formadores/mediadores e cursistas/estudantes.

Percebe-se, portanto, que o professor/tutor é visto como a gente de ação formadora, tem a responsabilidade de promover um ensino de qualidade, com equidade (BRASIL, 1986), de modo que os mais variados ambientes de aprendizagem possam estabelecer relação de troca, de direitos, e de responsabilidades, atuações que convergem para aprendizagem significativa em todos os âmbitos de ensino.

Assim, fica entendido que este profissional da educação precisa necessariamente imergir no processo de conscientização que prime pelo conhecimento de forma holística, considerando ser este processo, fundamental para um ensino que acolhe e torna significativo a presença de todos os estudantes nos contextos de aprendizagens. Pois "o profissional gera a situação globalmente, mas mobiliza algumas competências específicas independentes uma das outras, para tratar certos aspectos do problema." (PERRENOUD, 2000, p.16).

Imbuídos pelos desafios propostos, neste caso, as mudanças atuais ocorridas nos últimos tempos em relação ao processo de educação à distância, tornou-se fonte de investigação e o tutor/formador/mediador que tem se tornado cada vez mais alvo de um sistema em constante transformações. Por isso, a prática pedagógica virtual deve promover autonomia entendendo que "à nossa cultura fixada na palavra corresponde a nossa inexperiência do diálogo, da investigação, da pesquisa, que, por sua vez, estão intimamente ligados à criticidade, nota fundamental da mentalidade democrática." (FREIRE, 1967, p. 96).

Portanto, insistir no diálogo proposto por Paulo freire é manter viva a comunicação interativa, considerando, neste caso, essencial para construção de um ensino aberto as novas mudanças. Entender essa necessidade comunicativa é visualizar caminhos promissores no tocante ao ensino e aprendizagem em educação a distância. Essa premissa torna-se realidade quando o tutor/formador/mediador encontra caminhos subjetivos e coletivamente para atuar com destrezas em EaD. Esse profissional da educação necessita de conhecimentos, planejamento e acompanhamento sistemático subjacente a esta construção.

\section{Resultados e Discussões}

Durante a realização deste estudo, percebeu-se a relevância do professor enquanto tutor/formado/mediador que atua no contexto da educação virtual, não apenas para o processo de sistematização das atividades propostas, mas, necessariamente para assegurar o desenvolvimento eficaz do ensino e aprendizagem durante todo processo, ação promissora de diálogo e interação. Neste contexto é possível reconhecer na função do tutor sua relevância para atuação na educação em EaD e buscar nesta tarefa meios 


\section{-Revista de Iniciação à Docência, v.6, n.2, 2021- \\ Publicação: dezembro, 2021 - ISSN 2525-4332}

para um acompanhamento recíproco, ajudando os envolvidos reconhecer-se no ambiente com destreza e responsabilidade.

A modalidade de educação a distância, traz para o campo da educação novos debates inerentes as tecnologias da informação e comunicação -- TIC, fortalece o trabalho educativo, definindo-se enquanto possibilidade de expansão do conhecimento, sobretudo, para alunos participarem de forma significativa dos cursos em modalidade a distância. Essa ação exige, portanto, novos conhecimentos, sistematização das ações, diálogos e interatividade constante. Esse trabalho desenvolvido também pelos organizadores do curso construiu meios para uma comunicação assídua com os tutores considerados professores/formadores/mediadores.

Urge, dessa maneira, pensar em formas de estimular o estudante/cursista a acreditar no seu potencial, chamar a atenção para não ficarmos certos de certezas subjetivas, mas que procuremos vivenciar o novo, é "fundamental o conhecimento existente quanto saber que estamos abertos e aptos à produção do conhecimento ainda não existente." (FREIRE, 2002, p. 14).

Considerar que conseguimos influenciar, integrar, inquietar enquanto tutores é uma competência singular e necessária. Por isso, torna-se relevante atuar de forma ativa participando e interagindo sem perder o foco. Assim, o estudante/cursista se sente motivado ao diálogo, na busca pela construção do conhecimento, acreditando e vencendo barreiras. Esse trabalho ganha força quando realizado de forma criativa e humanizadora.

As experiências aqui descritas, assim como as vivências remetem aos estudos de Larrosa ao falar de experiência, pois para ele "o sujeito da experiência seria algo como um território de passagem, algo como uma superfície sensível que aquilo que acontece afeta de algum modo, produzir alguns afetos, inscreve algumas marcas, deixa alguns vestígios, alguns efeitos". (LARROSA, 2019, p.25).

É comum perceber nos ambientes de aprendizagens virtuais um distanciamento, porém, é sob o olhar do tutor que emerge estratégias que estimulem e promovam interações entre os envolvidos no processo. A globalização motivada pela nova forma de comunicação "online" imbricados pela linguagem digital constrói um universo de informação que emerge como uma nova cultura, hoje denominado cibercultura.

Essa ação garante formas de interagir criando possibilidades de produzir e compartilhar conhecimentos colaborativamente, potencializados pela comunicação a distância, sendo esta fundamental para interação de forma contínua e recíproca em que apresenta como elementos principais: o diálogo e a interação, definindo estratégias e ações comunicativas a serem desenvolvidas em variados ambientes virtuais de aprendizagens. 
Nesta relação, compreende-se que a comunicação digital consegue promover interatividade e construir significados. Assim, o diálogo ganha caráter positivo por propiciar uma comunicação interativa e participativa em EaD.

\begin{abstract}
Na medida, porém, em que amplia o seu poder de captação e de resposta às sugestões e às questões que partem de seu contorno e aumenta o seu poder de dialogação, não só com o outro homem, mas com o seu mundo, se "transitiva". Seus interesses e preocupações, agora, se alongam a esferas mais amplas do que à simples esfera vital. (FREIRE, 1967, p.59).
\end{abstract}

Podemos destacar aqui, o quanto a discussão se faz necessária para uma melhor atuação e ampliação para a permanente eficácia do ensino à distância, sendo as formações estratégias para o avanço do conhecimento e sua disseminação no que tange a atuação de tutor virtual. Esta confirmação se dá na fala do cursista quando revela sua satisfação em compartilhar sua concepção sobre as ações do tutor à distância:

"Muito bom, um curso sério e de estrutura e planejamento adequados. Ao tutor competente, interativo, dinâmico, atencioso com os alunos. Material de qualidade. E no meu ponto de vista, não teve aspectos negativos! Vale a pena fazê-Io" (Cursista 1).

Percebe-se, portanto, que o trabalho do tutor/formador/mediador permite uma interação significativa no ambiente virtual de aprendizagem, potencializa os cursistas/estudantes para uma participação proativa relevante para a co-criação do conhecimento inerente ao processo de produção ativa no campo da educação virtual. Hack (2010) demonstra essa importância do tutor e aborda que o acompanhamento do processo de ensino e aprendizagem ajuda o aluno nessa construção do conhecimento sensível às suas reais necessidades, sobretudo, na "relação afetiva para que o aluno se sinta aceito e tenha liberdade para cometer equívocos, já que errar faz parte do processo de aprendizagem" (HACK, 2010, p. 121).

Fica evidente, a necessidade de interação e de um diálogo contínuo para o acompanhamento das ações propostas, essa ação vai contribuir para encontrar caminhos e perceber que o estudante/cursista não está sozinho nesta trajetória de ensino. Esse pensamento vai culminar com a opinião da cursista quando apresenta sua opinião em relação a esse aspecto.

“Houve uma boa parceria entre a tutora responsável pela mediação do curso e os alunos. Houve muita interação com a turma e muita responsabilidade na troca de informação $e$ acompanhamento de todo os processos de ensino". (Cursista 2).

Nessa construção, percebe-se que o papel do tutor, enquanto mediador é de estreitar a relação de interatividade e provocar o cursista manter-se ativo no curso. Perrenoud, esclarece que o professor no "sabor de sua experiência" constrói novos saberes e acumula outros, portanto, uns tornam-se comunicáveis outros não, de forma que esses saberes não são "organizadores adequados de um referencial de competências" (2000, p.18). Esse autor, nos ensina que, adquirir competências é algo 
processual e contínuo, essencial na implementação das ações cotidianas compartilhar saberes e ramificar experiências nos ambientes produtivos de aprendizagens.

É preciso construir na coletividade laços afetivos, pautada numa relação harmoniosa, principalmente na troca de feedbacks com os cursistas/estudantes. Informase, portanto, que seu trabalho deve partir da reflexão, planejamento e sistematização do tempo/atividades. Essas ações são percebidas na devolutiva avaliativa da cursista onde relata fatos sentidos durante as atividades.

"Adorei o curso, a escolha do tema, dos textos, das discussões! As informações assim como a troca de mensagens e experiências foram valiosíssimas!" (Cursista 3).

Há que se considerar a relevância das ações desenvolvidas e sua relação de aprendizagem no ambiente virtual, a tutoria realiza uma intercomunicação cursistaestudante, de forma a superar dificuldades /necessidades constantes para o trabalho da mediação pedagógica em EaD, premissa relata pela cursista em processo de avaliação do curso.

"O mediador precisa ter atitude proativa, que antecipe necessidades e dificuldades, no intuito de acompanhar as aprendizagens dos alunos, com interação e aprendizagem coletiva."

(Cursista 4).

Esse pensamento também é trazido por uma das estudantes/cursistas quando percebe no trabalho do tutor/mediador significado no acompanhamento para realização das atividades no ambiente de aprendizagem virtual. Nessa ótica podemos concluir que o trabalho do tutor não é apenas o de conduzir ou avaliar para dar uma nota, mas constitui mediação/acompanhamento/intervenção, numa tarefa de criar situações e trazer o estudante/cursista à conexão com os conteúdos, com os objetivos ali propostos e, no processo desses feedbacks, construir novos significados, surge o insight ${ }^{5}$ que representa entendimento do curso numa maior proporção ao ensino e aprendizagem virtual.

Nesta perspectiva, entende-se que conjuntamente professor e aluno alcançam os objetivos propostos no curso por utilizar várias ferramentas para essa interlocução, a exemplo - os fóruns. "O grande objetivo no processo avaliativo é desenvolver no alunado a cooperação, autonomia, colaboração, posicionamento crítico e capacidade de transformar a realidade social através de práticas que ajudem a sociedade a viver com mais dignidade e respeito." (RODRIGUES, 2013, p.46).

Ainda, somam-se a esses feedbacks a comunicação e o diálogo como poder regulador no processo evolutivo entre o tutor e o aluno --- motivação e aprendizagem. Pois, deles dependem particularidades pessoais, emocionais e sociais para a efetivação no curso. Comin ao abordar essa temática diz que "fóruns de discussão partem de uma proposição inicial e vão se desenvolvendo com a construção conjunta de alunos e tutores." (2013, p. 340).

\footnotetext{
5 O termo insight representa aqui o entendimento do que que foi proposto pelo curso: "Mediadores Pedagógicos Digitais para EaD.
} 
Contudo, deve o professor de EaD/tutor "on-line" enfrentar os desafios de ordem tecnológica, técnicos, de conexão, desinteresse, desmotivação e outros tão grandes desafios dessa metodologia de ensino adaptando-se às demandas do mundo atual.

Compete ao professor/tutor novos critérios pedagógicos à aprendizagem significativa do seu trabalho para o estudante que é o objetivo maior, que alcance à sua desenvoltura participativa na aprendizagem em todos os momentos das atividades. Essa questão tem caráter de abordagem ao desenvolvimento de competências discutidas aqui por Perrenoud.

Entretanto, a relação entre tutores e cursistas promovem momentos contínuos de aprendizagens, interação e feedbacks, construindo laços de afetividade, trabalho responsável e dinâmico desenvolvido no curso. Masetto (2000) descreve que o perfil do professor que se coloca na atribuição de facilitador, mediador da aprendizagem tem como pressuposto o acompanhamento do aprendiz e sua aprendizagem, na "Formação de Mediadores Pedagógicos Digitais para a EAD". As tarefas executadas pelos cursistas/estudantes, envolviam a atuação dos tutores no ambiente virtual e tinha o objetivo de construir novos significados no campo da educação virtual.

Ademais, através deste curso foi possível compreender o quanto a comunicação é uma ferramenta importante para o alcance dos objetivos pedagógicos e educacionais da formação do cursista/estudante em cursos virtuais. Essa percepção faz jus a fala da cursista quando acrescenta:

\section{"Também podemos considerar como barreira a ser vencida, a desmotivação dos alunos pela falta do contato presencial do aluno com o professor ou do Estar junto virtual" (Cursista 6).}

Torna-se, portanto, necessário pensar o trabalho formativo nas plataformas digitais priorizando o diálogo e interação, trazendo para o campo do conhecimento virtual ramificação mediadas pela objetividade e criatividade. Neste sentido, a avaliação do trabalho realizado ganha força e suscita novos saberes e fazeres em EaD. Almeida (2018), insere para tanto, a necessidade de avaliar as ações desenvolvidas por uma dualidade de percepções, neste caso, fazendo a mediação entre tutor e cursista/estudante, concretizando a realização de um trabalho coerente com a prática coletiva e participativa em plataformas digitais.

Essa reflexão avaliativa contribui para reconhecer que, "a avaliação da aprendizagem possibilita a tomada de decisão e a melhoria da qualidade de ensino, informando as ações em desenvolvimento e a necessidade de regulações constantes". (ALMEIDA, 2018, p.64). Neste sentido, a tecnologia digital, mais precisamente o Ambiente Virtual de Aprendizagem-AVA é ferramenta para criação de novos saberes essenciais para os envolvidos nesta dinâmica de aprendizagem. 


\section{Considerações Finais}

Este trabalho visa possibilitar aos estudos da educação virtual a construção de novos saberes imbuídos pela complexidade da ação educativa e sua relação com a multiplicidade dos aspectos da dialogicidade e interatividade, numa perspectiva desafiadora a aprendizagem significativa, entendendo como fundamento a personalização do ensino com foco na mediação pedagógica entre os sujeitos participantes dos ambientes virtuais de aprendizagem.

Estas variáveis se concretizam através das relações entre os cursistas/estudantes e os tutores/formadores/mediadores e no desenvolvimento das novas competências, relevantes para mudança de atitudes, percebendo sobre os aspectos da realidade atual necessidades e possibilidades para uma nova atuação em EaD.

Nesta dinâmica de aprendizagem mediada pelo trabalho realizado pelo do tutor/formador/mediador fomenta saberes essenciais ao campo pedagógico, sobretudo, ganha sentido por evidenciar parâmetros para novas atuações em contextos educativos. Pode-se dizer que diante da estrutura, leituras, estudos, fóruns, feedbacks, avaliações acompanhamentos no curso de formação o pensar sobre a ação educativa faz toda diferença para essa construção.

Fica explícito que o diálogo e a interação são fermentas promissoras que contribuem nas relações comunicativas em ambientes virtuais de aprendizagem principalmente quando essa mediação conta com um profissional comprometido e coerente com uma comunicação ativa entre os sujeitos. O estudo de Paulo Freire foi fundamental para essa compreensão entendendo que o "estar junto virtual" exige disponibilidade e responsabilidade com a missão de educar em plataformas digitais.

\section{Referências}

ALBUQUERQUE, D. I. P; SCHLÜNZEN, E. T. M. O tutor e à docência virtual: os desafios para a prática pedagógica na EaD. Brasil: Capes, NeaD - Unesp; Portugal: UAb, 2018. (Material do curso Formação de Formadores para a mediação on-line).

ALMEIDA, Karina Carvalho de. Instrumentos, estratégias, critérios de avaliação da aprendizagem na Educação a Distância - EAD. Multifaces, v.1, n.1, abril, 2018, p.62-74. ALVES, Alda Judith. O Planejamento de Pesquisas qualitativas em Educação. Cad. Pesq. São Paulo (77): 53-61, maio 1991.

BRASIL. Lei de Diretrizes e Bases da Educação Nacional. Lei número 9394, 20 de dezembro de 1996.

COMIN, Fabio Scorsolini. Avaliação dos processos de ensino-aprendizagem em ações educacionais ofertadas à distância. Temas em Psicologia, v. 21, n. 2, p. 335-346, 2013. Disponível em: <http://pepsic.bvsalud.org/pdf/tp/v21n2/v21n2a03.pdf>. Acesso em: 05/04/2020. 
DUARTE, Rosália. Novas tecnologia, uma nova subjetividade? Revista Novamerica. № 110 , PP. 48-53, abr-jun 2006. In: CANDAU, Vera Maria; SACAVINO, Susana Beatriz. (Org.). Educação: temas em debate - 1 ed. Rio de Janeiro. 7Letras, 2015.

FAGUNDES, Léa. Os caminhos da inclusão digital no Brasil podem servir à educação libertadora das atuais e das próximas gerações. Pátio revista pedagógica. n.26, Porto Alegre. Maio/junho 2003.

FERNANDES, Siddaharta. Novas dimensões da aprendizagem: alunos e professores como produtores culturais. Revista Novamerica. $N^{\circ} 110$, PP. 20-23, abr-jun 2006. In: CANDAU, Vera Maria; SACAVINO, Susana Beatriz. (Org.). Educação: temas em debate - 1 ed. Rio de Janeiro. 7Letras, 2015.

FREIRE, Paulo. Pedagogia da Autonomia: Saberes necessários à prática docente. $25^{\mathrm{a}}$ Edição. São Paulo: Paz e Terra, 2002 (Coleção Leitura).

FREIRE. Paulo. Educação Como Prática da Liberdade. Paz e Terra, Rio de Janeiro, GB, Brasil, 1967.

HACK, Josias Ricardo. Comunicação dialógica na educação superior à distância: A importância do papel do tutor. Signo pensam, Bogotá, v. 29, n. 56, p. 114-123, 2010. Disponível em: http://www.scielo.org.co/scielo.php?script=sci_arttext\&pid=S0120$48232010000100007 \& \operatorname{lng}=e n \& n r m=i s o$. Acesso em 04/04/2020.

LARROSA, Jorge. Tremores: escritos sobre experiência. 1 ed. 1 reimp. Belo Horizonte: Autêntica, editora, 2015.

MASETTO, Marcos T. Mediação Pedagógica e o uso da tecnologia. In: Novas tecnologias e Mediação Pedagógica. Campinas: Papirus, 2000.

OLIVEIRA, Carla Padrel de; LENUZZA, Carlos; SCHLÜNZEN, Junior, Klaus, org. - Projeto UNESP, UAb e CAPES [Em linha]: formação de mediadores pedagógicos digitais para a educação a distância. Lisboa: Universidade Aberta, 2021. 66 p. (eUAb. Educação a Distância e eLearning; 13). ISBN 978-972-674-894-6.

OTA, M. Tendências atuais de estratégias pedagógicas: personalização, gamificação e trilhas de aprendizagem. Brasil: Capes, NEaD - Unesp; Portugal: UAb, 2018. (Material do curso Formação de Formadores para a mediação on-line).

PERRENOUD, Philippe. Dez novas competências para ensinar - Trad. Patrícia Chittoni Ramo - Porto Alegre: Artmed, 2000.

PRODANOV, Cleber Cristiano; FREITAS, Ernani Cesar. Metodologia do trabalho científico: métodos e técnicas da pesquisa e do trabalho acadêmico. 2. ed. Novo Hamburgo: Feevale, 2013.

RIOS, G.A. Sugestões para a mediação pedagógica inclusiva. Brasil: Capes, NEaD Unesp; Portugal: UAb, 2018. (Material do curso Formação de Formadores para a mediação online).

RODRIGUES, Nice Vânia Machado. Avaliação da Aprendizagem em Educação a distância através do fórum (Interface Educacional). Interfaces Científicas - Educação • Aracaju • V.01, N.03, p. 43-53, jun. 2013. Disponível em:file:///C:/Users/valdi/Documents/ARTIGO\%20REVISTA/488-Texto\%20do\%20artigo-28941-10-20130625.pdf. Acesso em: 12/08/2021. 
SEVERINO, Antônio Joaquim. Metodologia do trabalho científico. $23 .{ }^{\text {a }}$. ed. Ver. e atual. São Paulo: Cortez, 2007

TARDIF, Maurice; LESSARD, Claude. O Trabalho docente: Elementos para uma teoria da docência como profissão de interações humanas. 2014.

THIOLLENT. M. Metodologia da pesquisa-ação. São Paulo: Cortez; 1986.

THIOLLENT. M. Pesquisa-ação nas organizações. São Paulo: Atlas; 1997.

TARDIF, Maurice; LESSARD, Claude. O Trabalho docente: Elementos para uma teoria da docência como profissão de interações humanas. 2014. 